\title{
Pengaruh Pemanfaatan Dana Bantuan Operasional Kesehatan terhadap Upaya Kesehatan Anak melalui Posyandu di Indonesia Berdasarkan Data IFLS Tahun 2014
}

\author{
The Effect of Utilizing Health Operational Assistance Funds on Children's \\ Health Efforts Through on Integrated Health Center (IHC) in Indonesia \\ Based on 2014 IFLS Data
}

\author{
Nia Priyatiningsih", Atik Nurwahyuni \\ Fakultas Kesehatan Masyarakat, Universitas Indonesia, Depok, Indonesia \\ ("niapriyatiningsih@gmail.com)
}

\begin{abstract}
ABSTRAK
Dana Bantuan Operasional Kesehatan (BOK) merupakan upaya pemerintah Indonesia dalam mengurangi angka kematian bayi baru lahir dan balita. Tahun 2017 angka kematian bayi baru lahir mencapai 15 per 1000 kelahiran hidup dan 32 per 1000 kelahiran hidup pada balita. Dana BOK digunakan sebagai biaya operasional tenaga kesehatan/kader dalam melaksanakan kegiatan promotif dan preventif di luar gedung. Penelitian ini bertujuan menjelaskan pengaruh dana BOK dalam upaya kesehatan anak melalui posyandu. Penelitian ini menggunakan studi data sekunder IFLS tahun 2014, dengan desain studi cross-sectional dan pendekatan ekonometri model logit. Responden dalam penelitian ini adalah orang tua yang memiliki anak berusia 0-59 bulan, jumlah responden sebanyak 4.417. Proses pengolahan data menggunakan aplikasi STATA. Hasil penelitian menunjukkan anak yang dibawa ke posyandu berhubungan signifikan dengan p-value $<0,1$ terhadap status pendidikan ibu, status ekonomi dan Dana BOK. Status pendidikan memiliki p-value $=0,087$, status ekonomi memiliki p-value $=0,019$, dan dana BOK memiliki p-value=0,0001. Dana BOK tidak berpengaruh langsung terhadap kesehatan anak, tetapi pemanfaatkan Dana BOK oleh tenaga kesehatan/kader dapat memberi kesadaran ibu yang memiliki balita untuk menjaga kesehatan anak melalui posyandu.
\end{abstract}

Kata kunci : BOK, dana, posyandu, ekonometri

\section{ABSTRACT}

Health Operational Aid Fund (BOK) is an effort of the Indonesian government to reduce mortality of newborns and toddlers, where in 2017 mortality rate of newborns reached 15 per 1000 live births and 32 per 1000 live births for toddlers. BOK funds are used as operational costs for health workers/cadres in carrying out promotional and preventive activities outside the building. This study aims to explain the effect of BOK funds on child health efforts through on Integrated Health Center (IHC). This study used a secondary data study of 2014 IFLS, with a cross-sectional study design and logit econometric model approach. Respondents in this study was parents who have children aged 0-59 months, number of respondents was 4,417. Data processing used the STATA application. Results of study showed that children who were brought to IHC were significantly associated with p-value $<0.1$ on maternal education status, economic status and BOK Fund. Educational status has a p-value of 0.087, economic status has a p-value of 0.019, and BOK funds have a p-value of 0.0001. BOK funds do not directly affect children's health, but the utilization of BOK fund by health workers/cadres can provide awareness of mothers who have toddlers to maintain children's health through on IHC.

Keywords : BOK, fund, integrated health center, econometric

Copyright (C) 2019 by author. This is an open access article under the CC BY-NC-SA license

(https://creativecommons.org/licenses/by-nc-sa/4.0/).

DOI : http://dx.doi.org/10.30597/mkmi.v15i3.6286 


\section{PENDAHULUAN}

Para pemimpin dunia pada tahun 2015 , menyetujui 17 tujuan untuk dunia yang lebih baik pada tahun 2030, atau disebut dengan Sustainable Development Goals (SDGs), salah satu tujuan SDGs adalah kesehatan yang baik dan kesejahteraan bagi semua usia yang memiliki target setiap negara dapat mencegah dan menurunkan angka kematian bayi baru lahir dan balita setidaknya kurang dari 12 per 1000 kelahiran dan kematian balita 25 per 1000 kelahiran. ${ }^{1}$

Tujuan pembangunan berkelanjutan sangat penting dalam pencegahan kematian primer dan sekunder karena kelainan bawaan, komplikasi kelahiran prematur, cedera dan kematian akibat pneumonia. Antara tahun 1996 dan 2015, angka kematian balita di Tiongkok menurun dari 50,8 per 1.000 kelahiran hidup menjadi 10,7 per 1.000 kelahiran hidup, dengan tingkat pengurangan ratarata tahunan 8,2\%. Namun, 181.600 anak-anak masih meninggal sebelum ulang tahun kelima mereka, dengan 93.400 (51,5\%) kematian terjadi pada neonatus. ${ }^{2}$ Sedangkan angka kematian bayi baru lahir di Indonesia pada tahun 2017 sebesar 15 per 1000 kelahiran hidup dan angka kematian balita 32 kematian per 1000 kelahiran hidup. ${ }^{3}$

Salah satu upaya agar tercapainya tujuan SDGs di Indonesia dengan mendekatkan fasilitas kesehatan anak berupa Pos Pelayanan Terpadu (Posyandu) dimasyarakat. Posyandu merupakan kegiatan Upaya Kesehatan Bersumberdaya Masyarakat (UKBM) yang dikelola dari masyarakat dan untuk masyarakat. Pelayanan yang terdapat di Posyandu berupa penimbangan anak, pengukuran tinggi badan anak, imunisasi, vitamin A, makanan tambahan, pemantauan tumbuh kembang anak dan pemeriksaan kesehatan rutin anak. ${ }^{4}$

Menurut penelitian Erpian anak yang memanfaatkan posyandu dengan baik memiliki status gizi yang baik. ${ }^{5} \mathrm{Hal}$ ini sejalan dengan penelitian Merry Lanoh yaitu balita yang memanfaatkan pelayanan di posyandu memiliki gizi yang lebih baik dibandingkan balita yang tidak memanfaatkan posyandu. ${ }^{6}$

Penelitian di Ghana menyebutkan banyak faktor yang menyebabkan rendahnya kunjungan ke fasilitas kesehatan pelayanan kesehatan anak seperti tidak dapat diaksesnya layanan, kendala keuangan rumah tangga, kesulitan transporta- si, jadwal yang tidak sesuai, tempat yang tidak nyaman dan waktu tunggu yang lama. Selain itu, penyedia layanan menyebutkan pengetahuan perawat tentang pentingnya imunisasi, beban kerja yang berlebihan pada petugas kesehatan yang kurang staf. Pemerintahan Ghana mengoptimalkan kunjungan tenaga kesehatan ke rumah penduduk untuk menjaring kesehatan ibu. ${ }^{7}$

Dukungan pemerintah dalam upaya promotif dan preventif agar ibu memanfaatkan Posyandu yaitu dengan meluncurkan dana Bantuan Operasional Kesehatan (BOK) yang ditujukan untuk pemerintah daerah. Dana BOK diluncurkan pada tahun 2010 sebagai dana operasional di luar gedung. ${ }^{8}$ Adanya Dana BOK membantu menyelesaikan berbagai masalah kesehatan dalam bidang Kesehatan Ibu dan Anak sehingga dapat mencapai target SPM bidang kesehatan. ${ }^{9}$ Pemanfaatan dana BOK yang optimal dapat meningkatkan cakupan kesehatan ibu dan anak, jika dilakukan sesuai petunjuk teknis BOK dan dapat menekan kasus kematian ibu dan bayi di wilayahnya. ${ }^{10}$

Dana BOK digunakan untuk operasional petugas/kader kesehatan sebagai dana operasional di luar gedung seperti transport petugas/kader kesehatan untuk melakukan kegiatan promotif dan preventif upaya kesehatan anak yaitu untuk transportasi penyuluhan, pembelian bahan makanan tambahan penyuluhan, pemulihan, bahan komunikasi, informasi, edukasi yang dibutuhkan untuk konsumsi pertemuan. ${ }^{8}$ Tersedianya dana BOK membantu petugas/kader kesehatan menjangkau pelayanan yang lebih luas, ketercukupan dana mampu meningkatkan kinerja petugas/kader kesehatan untuk memberikan kesadaran ibu membawa balita ke Posyandu. ${ }^{11}$ Penelitian Mulyawan menyatakan dengan adanya dana BOK meningkatkan motivasi petugas/kader kesehatan untuk melakukan kegiatan promotif dan preventif karena dengan adanya dana BOK petugas/kader kesehatan lebih mudah dalam menjalankan kegiatan karena terdapat input finansial dalam kegiatan tersebut. ${ }^{12}$ Penelitian Maryati hubungan insentif/finansial terhadap efektifitas kegiatan di Posyandu berpola positif artinya semakin baik insentif yang diberikan untuk petugas/kader kesehatan maka semakin efektif kegiatan di posyandu. ${ }^{13}$ Petugas/kader kesehatan harus mampu berkomunikasi dengan efektif baik dengan individu, kelompok dan ma- 
syarakat. ${ }^{14}$ Petugas/kader kesehatan sebagai pemberi informasi kepada masyarakat dan juga sebagai penggerak masyarakat untuk meningkatkan derajat kesehatan di wilayahnya. ${ }^{1}$ Petugas/kader kesehatan harus dapat menjaga kualitas pelayanan kesehatan posyandu dengan menjalin hubungan yang baik dengan ibu-ibu balita. ${ }^{15}$ Hubungan interpersonal atau kedekatan antara petugas/kader kesehatan mempengaruhi kunjungan bayi dan balita ke Posyandu. ${ }^{16}$ Upaya kesehatan anak tidak hanya tanggung jawab petugas/kader kesehatan dan pemerintah, tetapi juga tanggungjawab dari masyarakat dan faktor individu dari ibu yang memiliki balita. Oleh karena itu, penelitian ini bertujuan untuk melihat pengaruh dana BOK terhadap kesehatan anak melalui pemanfaatan pelayanan kesehatan Posyandu.

\section{BAHAN DAN METODE}

Penelitian ini menganalisis data sekunder dengan menggunakan data Indonesia Family Life Survey (IFLS) atau di Indonesia dikenal dengan SAKERTI (Survei Aspek Kehidupan Rumah Tangga Indonesia) tahun 2014. Lokasi penelitian di Jawa Barat, Jawa Tengah, DKI Jakarta, Banten, Bali, NTB, Sulawesi Selatan, Kalimantan Selatan, Sumatera Selatan, Lampung, Sumatera Barat dan Sumatera Utara. ${ }^{17}$ Sampel dalam penelitian ini adalah orang tua yang memiliki anak yang berusia 0-59 bulan, dengan jumlah responden sebanyak 4.417 responden, menganalisis hubungan antar variabel yang diekspresikan dalam bentuk persamaan yang menghubungkan variabel dependen dengan satu atau lebih variabel independen digunakan metode analisis regresi. ${ }^{18}$ Analisis regresi yang digunakan adalah regresi logit untuk mengetahui pengaruh pemanfaatan dana BOK terhadap upaya kesehatan anak melalui pemanfaatan pelayanan posyandu di Indonesia dengan analisis univariat, bivariat dan uji logistic regression.

\section{HASIL}

Hasil analisis univariat menggambarkan sebaran frekuensi dan persentase pengaruh dana BOK terhadap upaya kesehatan anak melalui posyandu. Variabel dependen adalah upaya pelayanan kesehatan anak ke Posyandu sedangkan variabel independen adalah tingkat pendidikan ibu, tempat tinggal, status pekerjaan, status ekonomi dan dana

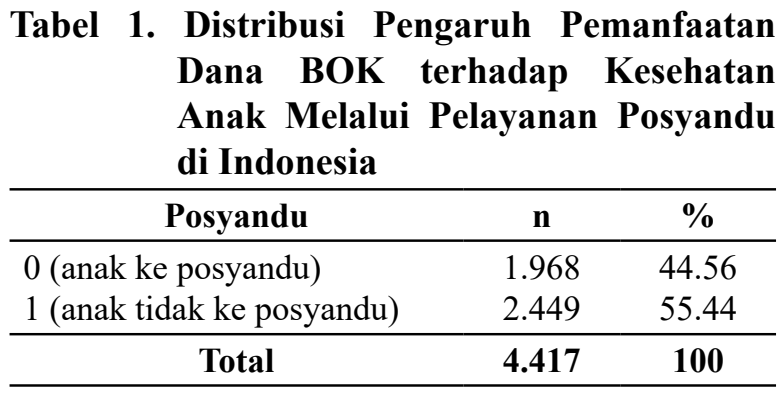

Tabel 2. Distribusi Sosiodemografi Responden di Indonesia

\begin{tabular}{lcc}
\hline \multicolumn{1}{c}{ Posyandu } & n & $\mathbf{\%}$ \\
\hline Status Pendidikan & & \\
$\quad$ Rendah (SD-SMP) & & \\
$\quad$ Tinggi (SMA-PT) & 2.438 & 55.20 \\
Pekerjaan Ibu & 1.979 & 44.80 \\
$\quad$ Tidak Bekerja & & \\
$\quad$ Bekerja & 2.837 & 64.23 \\
Tempat Tinggal & 1.580 & 35.77 \\
$\quad$ Kota & & \\
$\quad$ Desa & 2.418 & 54.74 \\
Status Ekonomi & 1.999 & 45.26 \\
$\quad$ Kuintil 1 & 1.235 & 27.96 \\
$\quad$ Kuintil 2 & 1.079 & 24.43 \\
$\quad$ Kuintil 3 & 982 & 22.23 \\
$\quad$ Kuintil 4 & 725 & 16.41 \\
$\quad$ Kuintil 5 & 396 & 8.97 \\
Dana BOK & & \\
$\quad$ Pemanfaatan Dana BOK di & & \\
$\quad$ Posyandu & 4.417 & 100 \\
\hline
\end{tabular}

Sumber: Data Indonesia Family Life Survey, 2014

BOK. Hasil penelitian menunjukkan bahwa pada tahun 2014 responden yang melakukan upaya kesehatan anak melalui pelayanan posyandu di 13 Propinsi terpilih (data IFLS) yaitu sebesar 1.968 $(44.56 \%)$ sedangkan yang tidak melakukan upaya kesehatan anak ke posyandu sebanyak 2.449 $(54,44 \%)$ (Tabel 1$)$.

Distribusi sosiodemografi untuk responden di Indonesia pada variabel independen diperoleh rata-rata ibu memiliki pendidikan rendah (SDSMP) sebesar $2.438(55,20 \%)$ sedangkan responden pendidikan tinggi sebanyak 1.979 (44.80\%). Variabel pekerjaan, paling banyak ibu yang tidak bekerja sebesar $2.837(64.23 \%)$ sedangkan ibu yang bekerja sebanyak $1.580(35,77 \%)$. Sebanyak $2.418(54,74 \%)$ ibu bertempat tinggal dikota. Rata-rata responden memiliki status ekonomi yaitu kuintil 1 sebesar $27,96 \%$, kuintil 2 sebesar 
Tabel 3. Distribusi Pengaruh Pemanfaatan Dana BOK terhadap Kesehatan Anak Melalui Pelayanan Posyandu di Indonesia Berkarakteristik Sosial Demografi

\begin{tabular}{|c|c|c|c|c|c|c|}
\hline \multirow{3}{*}{ Variabel } & \multicolumn{4}{|c|}{ Kesehatan Anak } & & \\
\hline & \multicolumn{2}{|c|}{ Anak ke Posyandu } & \multicolumn{2}{|c|}{$\begin{array}{c}\text { Anak Tidak ke } \\
\text { Posyandu }\end{array}$} & \multicolumn{2}{|c|}{ Total } \\
\hline & $\mathbf{n}$ & $\%$ & $\mathbf{n}$ & $\%$ & $\mathbf{n}$ & $\%$ \\
\hline \multicolumn{7}{|l|}{ Status Pendidikan } \\
\hline Rendah (SD-SMP) & 1.154 & 47.33 & 1.284 & 52.67 & 2.438 & 100 \\
\hline Tinggi (SMA-PT) & 814 & 41.13 & 1.165 & 58.87 & 1.979 & 100 \\
\hline \multicolumn{7}{|l|}{ Pekerjaan Ibu } \\
\hline Tidak Bekerja & 1.297 & 45.72 & 1.540 & 54.28 & 2.837 & 100 \\
\hline Bekerja & 671 & 42.47 & 909 & 57.53 & 1.580 & 100 \\
\hline \multicolumn{7}{|l|}{ Tempat Tinggal } \\
\hline Kota & 1.069 & 44.21 & 1.349 & 55.79 & 2.418 & 100 \\
\hline Desa & 899 & 44.97 & 1.100 & 55.03 & 1.999 & 100 \\
\hline \multicolumn{7}{|l|}{ Status Ekonomi } \\
\hline Kuintil 1 & 593 & 48.02 & 642 & 51.98 & 1.235 & 100 \\
\hline Kuintil 2 & 542 & 48.02 & 537 & 49.77 & 1.079 & 100 \\
\hline Kuintil 3 & 404 & 41.14 & 578 & 58.86 & 982 & 100 \\
\hline Kuintil 4 & 301 & 41.52 & 424 & 58.48 & 725 & 100 \\
\hline Kuintil 5 & 128 & 32.32 & 268 & 67.68 & 396 & 100 \\
\hline \multicolumn{7}{|l|}{ Dana BOK } \\
\hline $\begin{array}{l}\text { Pemanfaatan Dana BOK di } \\
\text { Posyandu }\end{array}$ & 1.968 & 44.56 & 2.449 & 55.44 & 4.417 & 100 \\
\hline
\end{tabular}

$24,43 \%$, kuintil 3 sebesar $22,23 \%$, kuintil 4 sebesar $16,41 \%$ dan kuintil 5 sebesar $8,97 \%$ (Tabel 2).

Analisa Bivariat menampilkan distribusi variabel $Y$ dependen dengan masing-masing variabel indenpenden $(\mathrm{X})$. Deskripsi statistik menunjukkan hasil ibu yang berpendidikan rendah melakukan upaya kesehatan anak melalui posyandu yaitu sebesar $47,33 \%$ dibandingkan ibu yang memiliki pendidikan tinggi yaitu $41,13 \%$. Status ibu yang tidak bekerja lebih banyak melakukan upaya kesehatan anak melalui posyandu yaitu sebesar $45,72 \%$ dibandingkan ibu yang bekerja sebesar $42.47 \%$. Ibu yang melakukan upaya kesehatan anak melalui posyadu lebih banyak memiliki tempat tinggal di desa yaitu $44,97 \%$ dibandingkan dengan balita yang tinggal di kota yaitu sebesar $44.21 \%$. Ibu yang memiliki status ekonomi kuintil $1(48,02 \%)$ dan kuintil 2 (48,02\%) lebih banyak melakukan upaya kesehatan melalui posyandu dibandingkan dengan responden yang memiliki status ekonomi di kuintil yang lain, pemanfaatan dana BOK diposyandu sebesar $44.56 \%$ dimanfaatkan untuk pelayanan posyandu (Tabel 3).

Uji Asumsi Logit adalah model dengan variabel terikat berskala pengukuran nominal atau ordinal dinamakan dengan model pilihan kualitatif, dari hasil pengolahan data didapatkan model analisis logit yaitu Ibu dengan pendidikan rendah berpeluang sebesar $11,2 \%$ untuk membawa anaknya ke posyandu. Status Ibu yang tidak bekerja berpeluang membawa anaknya ke posyandu sebesar 6,9\% dibandingkan ibu yang bekerja. Responden yang bertempat tinggal di desa peluang untuk tidak membawa anaknya ke posyandu sebesar 7\% dibandingkan responden yang tinggal di kota. Individu dengan status kuintil 1 dan kuintil 2 berpeluang membawa anaknya ke posyandu sebesar $58,5 \%$ dan $68,3 \%$. Peluang dana BOK yang dapat dimanfaatkan oleh posyandu sebesar $43,6 \%$ (Tabel 4).

\section{PEMBAHASAN}

Hasil penelitian ini menunjukkan variabel yang secara signifikan mempengaruhi upaya kesehatan anak adalah status pendidikan ibu, faktor ekonomi rumah tangga (kuintil 1, kuintil 2 dan kuintil 5) dan dana BOK. Hasil penelitian status pendidikan menunjukan terdapat pengaruh yang signifikan antara status pendidikan ibu dengan ibu yang membawa anak ke posyandu, hasil penelitian 
Tabel 4. Hasil Uji Asumsi Logit Variabel Pemanfaatan Dana BOK terhadap Kesehatan Anak Melalui Pelayanan Posyandu di Indonesia terhadap Variabel Independen

\begin{tabular}{lccccc}
\hline \multicolumn{1}{c}{ Variabel } & \multicolumn{5}{c}{ Logit } \\
\cline { 2 - 6 } & $\begin{array}{c}\text { Koefisien } \\
\text { (Robust) }\end{array}$ & SE & $\begin{array}{c}\text { Marginal } \\
\text { Effect }\end{array}$ & SE & Odd Ratio \\
\hline Status Pendidikan & $-0.112^{*}$ & 0.065 & $-0,277$ & 0,016 & 1.11 \\
Pekerjaan & -0.069 & 0.064 & 0,017 & 0,015 & 1.07 \\
Tempat Tinggal & -0.073 & 0.063 & -0.018 & 0,015 & 1.07 \\
quintil 1 & $0.585^{* * *}$ & 0.127 & 0.145 & 0,031 & 0.55 \\
quintil 2 & $0.683^{* * *}$ & 0.127 & 0.169 & 0.031 & 0.50 \\
quintil 3 & $0.334^{* * *}$ & 0.128 & 0.082 & 0,029 & 0.71 \\
quintil 4 & $0.354^{* * *}$ & 0.132 & 0,088 & 0,033 & 0.70 \\
Lnbok & $0.436^{* * *}$ & 0.054 & 0,107 & 0,134 & 0.64 \\
Constant & -10.00 & 1.190 & --- & -- & 2.21 \\
Observation & 4417 & --- & --- & -- & -- \\
R-Squared & 0,021 & --- & -- & & \\
\hline
\end{tabular}

Standar errors in paranthese

${ }^{* * *} \mathrm{p}<0,01,{ }^{* *} \mathrm{p}<0,05,{ }^{*} \mathrm{p}<0,1$

Sumber: Data Indonesia Family Life Survey, 2014

ini sejalan dengan penelitian Idaningsih, terdapat hubungan yang signifikan antara pendidikan ibu dengan kunjungan ke posyandu..$^{19}$ Demikian halnya penelitian Elida terdapat hasil yang signifikan antara pendidikan ibu dengan perilaku baik kunjungan ke posyandu. ${ }^{20}$ Namun, berbeda hasil penelitian Darmawan tidak ada hubungan antara pendidikan orang tua dengan pemanfaatan pelayanan posyandu ( $\mathrm{p}$ value $>0,05$ ). Hasil dari analisis juga diperoleh nilai $\mathrm{OR}=0,985$ (95\%CI:0,499-1,944), artinya orang tua yang berpendidikan dasar mempunyai peluang 0,985 kali untuk berperilaku kurang dalam memanfaatkan pelayanan posyandu dibandingkan dengan orang tua yang berpendidikan lanjutan. ${ }^{21}$

Faktor sosial ekonomi dalam hal ini adalah pengeluaran dalam 1 rumah tangga dihitung berdasarkan per individu per bulan dalam hitungan kuintil 1, kuintil2, kuintil 3 dan kuintil4. Hasil penelitian menyebutkan ibu yang mempunyai pengeluaran pada kuintil 1 dan kuintil 2 mempunyai peluang membawa anak ke posyandu sebesar 0,50 dan 0,55 kali kali lebih tinggi daripada ibu yang mempunyai pengeluaran kuintil yang lain. Penelitian Nila menyebutkan faktor sosial ekonomi sangat mempengaruhi keaktifan ibu dalam kegiatan posyandu di Dusun Mlangi Kabupaten Sleman. ${ }^{22}$

Hasil penelitian variabel dana BOK menunjukkan hubungan signifikan dengan posyandu, dana BOK untuk upaya kesehatan anak sebesar
0,64 kali yang dimanfaatkan oleh Posyandu. Dana BOK diketahui sangat bermakna secara signifikan. Hal ini diduga kinerja Puskesmas dan jaringannya (posyandu) cukup baik dalam hal promotif dan preventif sehingga meningkatkan upaya kesehatan anak. Penelitian terdahulu FF Sondakh menunjukkan dana BOK dimanfaatkan untuk kegiatan preventif dan promotif di puskesmas seperti transport perjalanan petugas untuk kegiatan posyandu, kunjungan rumah, pemantauan, mini lokakarya lintas sektor. Dana BOK juga dimanfaatkan untuk kegiatan manajemen Puskesmas pembelian belanja barang seperti ATK, PMT, fotocopy sampai dengan konsumsi. ${ }^{23}$

Anggaran Pemerintah Daerah untuk upaya promotif dan preventif sangat terbatas, oleh karena itu kehadiran dana BOK sangat penting bagi Kabupaten/Kota dalam rangka menunjang Upaya Kesehatan Berbasis Masyarakat (UKBM). Adanya dana BOK dapat mewujudkan pemerataan akses pelayanan kesehatan di wilayah setempat melalui kegiatan promotif dan preventif yang dilakukan oleh puskesmas, poskesdes dan posyandu sehingga dapat memberikan manfaat kesehatan bagi masyarakat. ${ }^{24}$

Variabel lain dalam penelitian ini yang tidak bermakna secara signifikan dapat dijelaskan seperti pekerjaan ibu, pada ibu yang bekerja diduga berpengaruh terhadap upaya kesehatan anak dengan membawa ke posyandu. Namun, pada pene- 
litian ini hal itu tidak terbukti, terlihat dari $p$-value variabel pendidikan $p>0,05$ berdasarkan penelitian terdahulu Henlinda ${ }^{5}$ tidak ada hubungan faktor pekerjaan dengan kegiatan posyandu begitu juga dengan penelitian Risqi terdapat hubungan yang signifikan antara status pekerjaan dengan keaktifan ibu menimbangkan balita di Posyandu. ${ }^{25}$

Tempat tinggal di kota maupun di desa diduga mempengaruhi upaya kesehatan anak, karena pelayanan kesehatan anak berupa posyandu ada disetiap wilayah kelurahan baik didesa maupun dikota ${ }^{4}$ sehingga setiap rumah tangga mudah mendapatkan akses pelayanan masyarakat, tetapi dalam penelitian ini tempat tinggal tidak mempengaruhi upaya kesehatan anak. Hal ini sejalan dengan penelitian Fauziah ${ }^{14}$ bahwa tidak ada hubungan yang signifikan antara tempat tinggal dengan kunjungan ibu membawa balita ke posyandu.

\section{KESIMPULAN DAN SARAN}

Berkaitan dengan hasil penelitian, maka dapat disimpulkan selain faktor sosial seperti pendidikan ibu dan faktor ekonomi (status ekonomi kuintil 1 dan kuintil 2), ternyata salah satu faktor yang mempengaruhi upaya kesehatan anak adalah dana BOK, dana BOK yang digunakan oleh Puskesmas dan jaringannya (posyandu) mempengaruhi kesehatan anak. Posyandu merupakan fasilitas sarana masyarakat memperoleh pelayanan kesehatan disarankan dan informasi kesehatan tentang pembinaan gizi dan kesehatan anak. Saran yang diberikan kepada puskesmas dan jaringannya agar menyusun rencana kegiatan yang lebih strategis lagi dalam pemanfaatan dana BOK untuk kegiatan upaya kesehatan anak, untuk Dinas Kesehatan Propinsi dan kabupaten/kota membimbing dan memantau pemanfaatan dana BOK kepada para puskesmas dan jaringannya (posyandu) agar pemanfaatan Dana BOK tepat sasaran, untuk Kementerian Kesehatan dapat mengevaluasi program dana BOK dengan melihat pencapaian kunjungan posyandu berdasarkan faktor demografi di suatu wilayah tertentu, sehingga Kementerian Kesehatan tidak hanya melihat capaian realisasi saja yang dilaporkan oleh puskesmas namun Kementerian Kesehatan dapat melihat pengaruh pemanfaatan dana BOK dari faktor individu. Kementerian Kesehatan hendaknya menggalang komitmen dengan Dinkes Propinsi untuk mendorong keluarnya kebi- jakan terkait komitmen kab/kota untuk meningkatkan kinerja puskesmas dengan membina posyandu untuk upaya pelayanan kesehatan anak berupa promotif dan preventif dengan memnafaatkan dana BOK

\section{UCAPAN TERIMA KASIH}

Ucapan terima kasih kepada Badan Pengembangan dan Pemberdayaan Sumber Daya Manusia Kesehatan (BPPSDMK) Kementerian Kesehatan RI yang telah memberikan bantuan dana dalam pelaksanaan penelitian ini.

\section{DAFTAR PUSTAKA}

1. Kementerian Perencanaan Pembangunan Nasional, dan United Nations Children's Fund. Laporan Baseline SDG tentang AnakAnak di Indonesia. Jakarta: BAPPENAS dan UNICEF;2017:1-105. Available at: https:// www.unicef.org/indonesia/id/SDG_Baseline report.pdf.

2. He C, Liu L, Chu Y, et al. National and Subnational All-Cause and Cause-Specific Child Mortality in China, 1996-2015: a Systematic Analysis with Implications for the Sustainable Development Goals. The Lancet Global Health. 2017:186-197.

3. Badan Kependudukan dan Keluarga Berencana Nasional. Survei Demografi dan Kesehatan Indonesia 2017. Jakarta: BKKBN; 2018.

4. Kemenkes RI. Pedoman Umum Pengelolaan Posyandu. Jakarta: Kementerian Kesehatan; 2011.

5. Erpian H. Hubungan Pengetahuan Ibu, Pemanfaatan Posyandu dan Faktor Lainnya terhadap Status Gizi Balita di Wilayah Kerja Puskesmas Bromo Medan Tahun 2011. [Skripsi]. Depok: Universitas Indonesia; 2011.

6. Lanoh M, Sarimin S, Karundeng M. Hubungan Pemanfaatan Posyandu dengan Status Gizi Balita di Wilayah Kerja Puskesmas Ranotana Weru Kota Manado. Journal Keperawatan. 2015;3(2):1-7.

7. Agbozo F, Colecraft E, Jahn A, Guetterman T. Understanding Why Child Welfare Clinic Attendance and Growth of Children in the Nutrition Surveillance Programme is Below Target: Lessons Learnt from a Mixed Methods Study in Ghana. BMJ Nursing. 2018;17(25):1-14 
8. Kemenkes RI. Petunjuk Teknis BOK Tahun 2014. Jakarta: Kementerian Kesehatan; 2014.

9. Andersen RM. Revisiting the Behavioral Model and Access to Medical Care: Does it Matter? Journal of Health and Social Behavior. 1995;36(1):1-10.

10. Aridewi A, Kartasurya MI, Sriatmi A. Analisis Pemanfaatan Bantuan Operasional Kesehatan dalam Upaya Peningkatan Kesehatan Ibu dan Anak di Puskesmas Wilayah Kerja Dinas Kesehatan Kabupaten Kudus. Jurnal Manajemen Kesehatan Indonesia. 2013;1(1):32-40.

11. Beratha O, Wirakusuma IB, Sudibya IGA. Hubungan Karakteristik, Motivasi dan Dana BOK dengan Kinerja Petugas KIA Puskesmas di Kabupaten Gianyar. Public Health and Preventive Medicine Archive. 2013;1(1):29-34.

12. Mulyawan H, Trisnantoro L, Zaenab SN, et al. Evaluasi Pelaksanaan Kebijakan Bantuan Operasional Kesehatan di Dinas Kesehatan (Studi Kasus di Dinas Kesehatan Kabupaten Bantul dan Dinas Kesehatan Kabupaten Lebong Tahun 2011. Jurnal Kebijakan Kesehatan Indonesia. 2012;1(3):144-153.

13. Maryati H. Faktor Penentu Efektivitas Upaya Kesehatan Bersumberdaya Masyarakat (UKBM) Posyandu pada Dinas Kesehatan Kota Bogor Tahun 2015. [Tesis]. Depok: Universitas Indonesia; 2015.

14. Fauziah, Mardjan H. Hubungan Antara Faktor Reinforcing dan Aksesabilitas Posyandu dengan Kunjungan Ibu Membawa Anak Balita ke Posyandu di Desa Rasau Jaya 1. Jurnal Mahasiswa dan Penelitian Kesehatan. 2014;1(1):38-49.

15. Nur R, Handayani F. Hubungan Antara Kualitas Pelayanan Kesehatan Posyandu dengan Frekuensi Kunjungan Ibu Balita di Posyandu XI Serangan Sidoluhur Godean Sleman Yogyakarta. [Skripsi]. Yogyakarta: Sekolah Tinggi Ilmu Kesehatan 'Aisyiyah; 2012.

16. Sihotang HMI. Rahma N. Faktor Penyebab Penurunan Kunjungan Bayi di Posyandu Puskesmas Langsat Pekanbaru Tahun 2016. Jurnal Endurance. 2017;2(2):168-177.
17. The RAND Corporation. Indonesia Family Life survey (IFLS) 5. The Indonesia Family Life Survey (IFLS). [Internet]. [Diakses pada 20 Januari 2019]. Available at: https://www. rand.org/well-being/social-and-behavioral-policy/data/FLS/IFLS/ifls5.html.

18. Gujarati. Basic Econometrics. In: Basic Econometrics. McGraw-Hill Companies; 2004.

19. Idaningsih A. Faktor-Faktor yang Berhubungan dengan Kunjungan Balita ke Posyandu. Syntax Literate: Jurnal Ilmiah Indonesia. 2016;1(2):16-29.

20. Purba Elida Hairunida BR. Faktor yang Berhubungan dengan Perilaku Kunjungan ke Posyandu di Wilayah Kerja Puskesmas Pancoran Mas Kota Depok Tahun 2012. [Skripsi]. Depok: Universitas Indonesia; 2012.

21. Darmawan AAKN. Faktor-Faktor yang Mempengaruhi Perilaku Kunjungan Masyarakat terhadap Pemanfaatan Pelayanan Posyandu di Desa Pemecutan Kelod Kecamatan Denpasar Barat. Jurnal Dunia Keseha$\tan .2015 ; 5(2): 29-39$.

22. Sativa NE. Faktor-Faktor yang Berhubungan dengan Keaktifan Ibu Balita dalam Kegiatan Posyandu Dusun Mlangi Kabupaten Sleman. [Skripsi]. Yogyakarta: Sekolah Tinggi Ilmu Kesehatan 'Aisyiyah; 2017.

23. Gabriani F.F Sondakh, Franckie R.R Maramis FKK. Analisis Pemanfaatan dan Pengelolaan Dana Bantuan Operasional Kesehatan (BOK) di Puskesmas Sario Kota Manado. Media Kesehatan. 2017;9(3).

24. Asmaripa A. Pelaksanaan Kebijakan Bantuan Operasional Kesehatan di Kabupaten Ogan Ilir Sumatera Selatan. Jurnal Kebijakan Kesehatan Indonesia. 2012;1(1):7-12.

25. Sulistiyanti A, Untaraningsih RD. Hubungan Status Pekerjaan dengan Keaktifan Ibu Menimbangkan Balita di Posyandu Puri Waluyo Desa Gebang Kecamatan Masaran Kabupaten Sragen. Jurnal Ilmiah Rekam Medis dan Informatika Kesehatan. 2013;3(2):1-11. 